\title{
GENETIC AND MOLECULAR BIOLOGICAL ANALYSIS OF PROTEIN-PROTEIN INTERACTIONS IN CORONAVIRUS ASSEMBLY
}

\author{
Paul S. Masters, Lili Kuo, Rong Ye, Kelley R. Hurst, Cheri A. Koetzner, \\ and Bilan Hsue*
}

\section{INTRODUCTION}

Virions of coronaviruses (CoVs) are pleiomorphic, with a roughly spherical structure brought about by cooperation among a relatively small set of structural proteins and a membranous envelope acquired from the endoplasmic reticulum-Golgi intermediate compartment (ERGIC) (Fig. 1). Three integral membrane proteins reside in the envelope. The most salient of these is the spike glycoprotein $(\mathrm{S})$, which mediates receptor attachment and fusion of the viral and host cell membranes. The membrane protein $(\mathrm{M})$ is the most abundant virion component and gives the envelope its shape. The third constituent is the envelope protein (E), which, although minor in both size and quantity, plays a decisive role is envelope formation. In some group $2 \mathrm{CoVs}$, an additional protein, the hemagglutinin-esterase (HE), appears in the viral envelope. Finally, interior to the envelope, monomers of the nucleocapsid protein $(\mathrm{N})$ wrap the genome into a helical structure.

A number of approaches have been taken to elucidate the network of interactions, among the canonical structural proteins $\mathrm{S}, \mathrm{M}, \mathrm{E}$, and N, and the genomic RNA, that lead to assembly of virions. The earliest efforts employed the fractionation and reassociation of components of purified virions. These studies were followed by molecular genetic and co-immunoprecipitation analyses of expressed proteins or proteins from virus-infected cells. More recently, reverse-genetic techniques have become available. This chapter will briefly review the current understanding of CoV assembly, highlighting some recent results from our laboratory in the context of work that has been done by numerous other groups in this field.

From a large body of work extending over two decades, the main principle that has emerged is that $\mathrm{M}$ is the central organizer of $\mathrm{CoV}$ assembly. The $\mathrm{M}$ protein $(\sim 25 \mathrm{kDa})$

\footnotetext{
* Paul S. Masters, Lili Kuo, Rong Ye, Kelley R. Hurst, Cheri A. Koetzner, New York State Department of Health, Albany, New York. Bilan Hsue, Stratagene, La Jolla, California.
} 
has a small, amino-terminal ectodomain that is either O-glycosylated (group $2 \mathrm{CoVs}$ ) or $\mathrm{N}$-glycosylated (groups 1 and $3 \mathrm{CoVs}$ ) (Fig. 1). This domain is followed by three transmembrane segments and a large carboxy-terminal endodomain. ${ }^{1-4}$ For the group $1 \mathrm{CoV}$ $\mathrm{TGEV}$, it has been shown that roughly one-third of $\mathrm{M}$ protein assumes a topology in which part of the endodomain constitutes a fourth transmembrane segment, thereby positioning the carboxy terminus on the exterior of the virion ${ }^{5}$; however, this has not yet been demonstrated for other $\mathrm{CoV}$ family members.

The dominant role of $\mathrm{M}$ was, in part, deduced by the process of elimination. Early experiments with tunicamycin-treated MHV-infected cells showed that (noninfectious) virions could assemble without $\mathrm{S}$ protein. ${ }^{6,7}$ This finding was also consistent with the properties of an $\mathrm{S}$ gene $t s$ mutant, which failed to incorporate spikes into virions at the nonpermissive temperature. ${ }^{8}$ Careful co-immunoprecipitation studies subsequently demonstrated that $\mathrm{M}$ selects both the $\mathrm{S}$ and HE proteins for assembly. ${ }^{9,10}$ However, it was apparent that $\mathrm{M}$ could not act on its own: expression of $\mathrm{M}$ protein alone does not lead to formation of virion-like structures. In addition, $\mathrm{M}$, expressed in the absence of other viral proteins, travels to the Golgi, whereas CoVs bud into the ERGIC. ${ }^{11-15}$ This paradox was resolved by the landmark demonstration that co-expression of MHV M protein and a previously overlooked structural protein, E, resulted in the formation of virus-like particles (VLPs). ${ }^{16,17}$ That just the $\mathrm{M}$ and E proteins are necessary and sufficient for the formation and release of VLPs has since been shown for CoVs of all three groups: $\mathrm{BCoV}^{18}$ and SARS-CoV ${ }^{19}$ (group 2), $\mathrm{TGEV}^{18}$ (group 1), and $\mathrm{IBV}^{20,21}$ (group 3). To date, the only apparent exception is a report that, for SARS-CoV, M protein and $\mathrm{N}$ protein were necessary and sufficient for VLP formation. ${ }^{22}$ It remains to be seen whether this finding indicates a unique aspect of SARS-CoV virion morphogenesis, or whether it reflects a singular characteristic of the cell line or the expression system that was used.

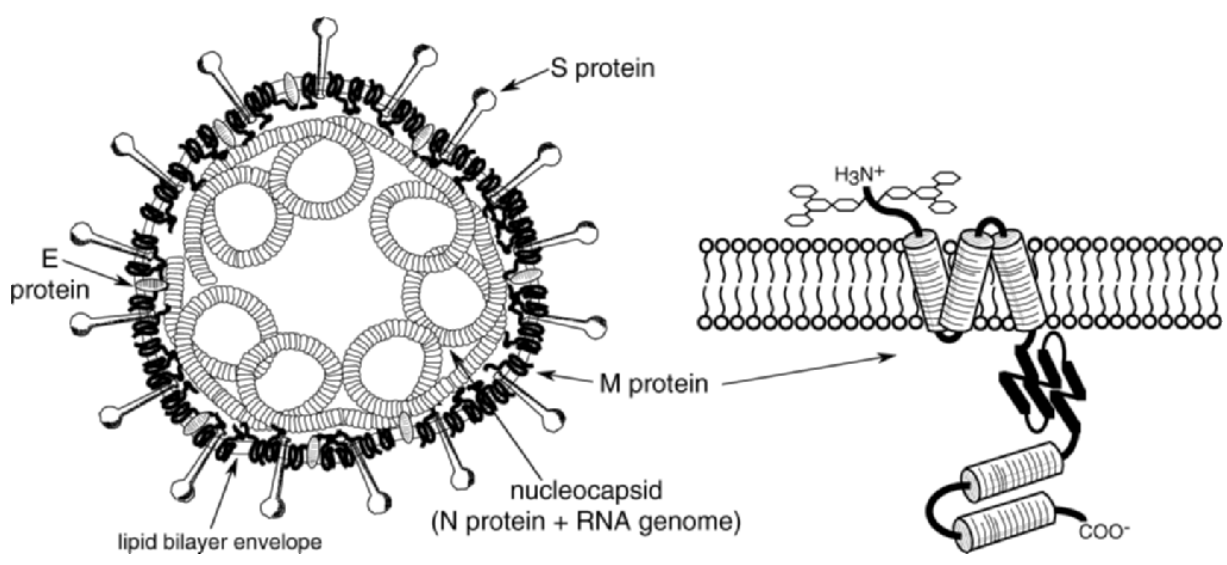

Figure 1. Structure of the $\mathrm{CoV}$ virion (left), and a model of the M protein (right). 


\section{INTERACTIONS OF S WITH M}

Experiments with VLPs made possible the systematic manipulation of individual constituents of the virion envelope, leading to the first glimpses of the function of $\mathrm{E}$ protein and the partial localization of M-S intermolecular interactions. ${ }^{23,24}$ The $\mathrm{S}$ protein is a large $(\sim 180 \mathrm{kDa})$ type I transmembrane protein that assembles into trimers to form the distinctive $\mathrm{CoV}$ spikes. Although it is not required for VLP formation, S protein, if present, becomes incorporated into VLPs. The heavily N-glycosylated amino-terminal ectodomain of S, which makes up more than $95 \%$ of the mass of the molecule, has been found to be essentially inert in the assembly process. Construction of chimeric MHVFIPV S proteins with swapped ectodomains showed that the 61-amino-acid transmembrane domain and endodomain determined the incorporation of the $\mathrm{S}$ protein into VLPs formed by the homologous $\mathrm{M}$ and E proteins. ${ }^{24}$

When this principle - the functional separation of the domains of $\mathrm{S}$ for receptor binding and for virion assembly - was extended to whole viruses, it allowed the development of host range-based selective systems for the reverse genetics of CoVs through targeted RNA recombination. ${ }^{25,26}$ A mutant of MHV (designated fMHV) was constructed, in which the ectodomain of the MHV S protein was replaced by that of the FIPV S protein. This chimeric virus had the host cell-restricted growth pattern that was predicted from its precursors: it had simultaneously lost the ability to grow in murine cells and gained the ability to grow in feline cells. The use of fMHV as the recipient virus in targeted RNA recombination enabled us to efficiently carry out reverse genetics on MHV, by restoring the MHV S ectodomain (in conjunction with mutations of interest) and selecting for the reacquisition of the ability to grow in murine cells. ${ }^{27}$ Selections of even greater stringency were subsequently made possible by the rearrangement of genes downstream of S, in fMHV.v2; this rearrangement effectively precluded the possibility of unwanted secondary crossover events during targeted RNA recombination. ${ }^{28}$

Among the many problems to which this system has been applied was the genetic dissection of the transmembrane domain and endodomain of the MHV S protein, in order to localize the determinants of S incorporation into virions. ${ }^{29}$ We used two strategies for this investigation (Fig. 2). First, the $\mathrm{S}$ protein transmembrane and endodomains were attached to a heterologous ectodomain to produce a surrogate virion structural protein (named Hook), which could be mutated without consequence to viral infectivity. Second, significant mutations from Hook were transferred to the $\mathrm{S}$ protein (in the absence of Hook), to enable examination of their effects on viral phenotype. We found that assembly competence mapped to the endodomain of $\mathrm{S}$, which was sufficient to target Hook for incorporation into virions. Further mutational analysis indicated a major role for the charge-rich carboxy-terminal region of the endodomain. Additionally, we found that the adjacent, membrane-proximal, cysteine-rich region of the endodomain is critical for cell-cell fusion during infection, thus confirming results previously obtained with $\mathrm{S}$ protein expression systems. ${ }^{30,31}$ A separate study ${ }^{32}$ came to the same fundamental conclusion that virion incorporation was determined by the endodomain of $\mathrm{S}$, but in the latter work the major role in assembly was ascribed to the cysteine-rich region of the endodomain. The differences among the detailed conclusions of these two studies may have been due to the relative importances of particular endodomain residues that were ablated in the differently constructed deletion mutants. 


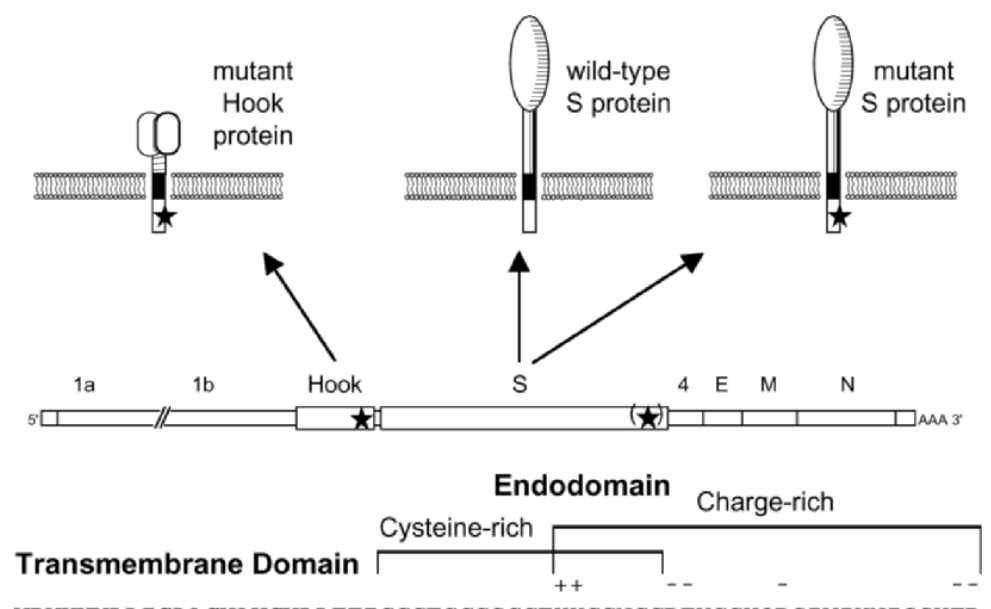

WPWYVWLLIGLAGVAVCVLLFFICCCTGCGSCCFKKCGNCCDEYGGHQDSIVIHNISSHED

Figure 2. Genetic dissection of the determinants for incorporation of the $\mathrm{S}$ protein into virions.

\section{INTERACTIONS OF N WITH M}

We have also examined the association between the $\mathrm{M}$ protein and the $\mathrm{N}$ protein of MHV. This was initially accomplished through the construction of a highly impaired mutant, $\mathrm{M} \Delta 2$, containing a two-amino-acid truncation of the $\mathrm{M}$ protein. ${ }^{27}$ This mutant formed tiny plaques and grew to maximal titers that were three orders of magnitude lower than those of the wild type. Analysis of multiple second-site revertants of $\mathrm{M} \Delta 2$ revealed a number of changes in either the $M$ protein or the $N$ protein that could individually compensate for the lesion in $\mathrm{M} \Delta 2$ (Fig. 3). The latter set of suppressors provided the first genetic evidence for a structural interaction between the $\mathrm{M}$ and $\mathrm{N}$ proteins, and they allowed that interaction to be localized to the carboxy termini of both proteins.

The MHV N protein $(\sim 50 \mathrm{kDa})$ comprises three conserved domains that are separated by two highly divergent spacer regions. ${ }^{33}$ Domains 1 and 2 , which make up most of the molecule, are very basic, and the RNA-binding capability of $\mathrm{N}$ maps to domain $2 .^{34,35}$ In contrast, domain 3 , the carboxy-terminal 45 amino acids of $\mathrm{N}$, has an excess of acidic over basic residues. To complement the results obtained with the $\mathrm{M} \Delta 2$ mutant, we recently created a complete set of clustered charged-to-alanine mutants in domain 3 of $\mathrm{N}^{36}$ One of these mutants, CCA4, was extremely defective, thereby implicating a pair of aspartate residues (D440 and D441) as making a major contribution by $\mathrm{N}$ protein to the $\mathrm{N}-\mathrm{M}$ interaction. Moreover, independent second-site reverting mutations of CCA4 were found to map in the carboxy-terminal region of either the $\mathrm{N}$ or the $\mathrm{M}$ protein (Fig. 3), thereby displaying genetic cross-talk reciprocal to that uncovered with the $M \Delta 2$ mutant. Indeed, one particular mutation in $N$ domain 3 (Q437L) was isolated multiple times, either as a suppressor of the $\mathrm{M} \Delta 2$ mutation or as a suppressor of the N CCA4 mutation. Additionally, we showed that the transfer of $\mathrm{N}$ protein domain 3 
to a heterologous protein (GFP) was sufficient to allow incorporation of GFP into MHV virions.

It is not yet clear how this genetically defined N-M interaction is related to connections that have been uncovered by molecular biological and biochemical means. For TGEV, the interaction between $\mathrm{N}$ and $\mathrm{M}$ was assayed by binding of in vitrotranslated $\mathrm{M}$ protein to immobilized nucleocapsid purified from virions. ${ }^{37}$ Deletion mapping was used to localize this binding to a region of the TGEV M protein, the MHV counterpart of which partially overlaps with critical residues that we have identified in the MHV M protein by suppressor mapping. A key early study of MHV, which used biochemical procedures to fractionate the components of purified virions, found a temperature-dependent association between nonionic detergent-solubilized $\mathrm{M}$ protein and the viral nucleocapsid. ${ }^{38}$ More recently, it was shown that $\mathrm{N}$ protein could be coimmunoprecipitated from $\mathrm{MHV}$-infected cells by mAbs specific for $\mathrm{M}$ protein. Significantly, although $\mathrm{N}$ was shown to be intracellularly associated with all viral RNAs, both subgenomic and genomic, ${ }^{39-41}$ the $\mathrm{M}$ protein bound only to those complexes of $\mathrm{N}$ molecules that were, in turn, bound to genomic RNA. ${ }^{41}$ Such selectivity was determined to depend upon the presence of the genomic RNA packaging signal; this signal, if transferred to a heterologous RNA, was sufficient to allow its packaging into virions. ${ }^{42}$ Surprisingly, further work with co-expressed MHV proteins and RNAs attributed the selection of packaging signal RNA to the M protein. ${ }^{43}$ Thus, VLPs composed of $M$ and $\mathrm{E}$, but not $\mathrm{N}$ protein, were found to incorporate an RNA molecule only if it contained the MHV packaging signal. Although the N-M interaction that we have localized genetically appears to be independent of RNA, it is conceivable that the accessibility of N protein domain 3 is modulated by the binding of $\mathrm{N}$ to particular RNA substrates.

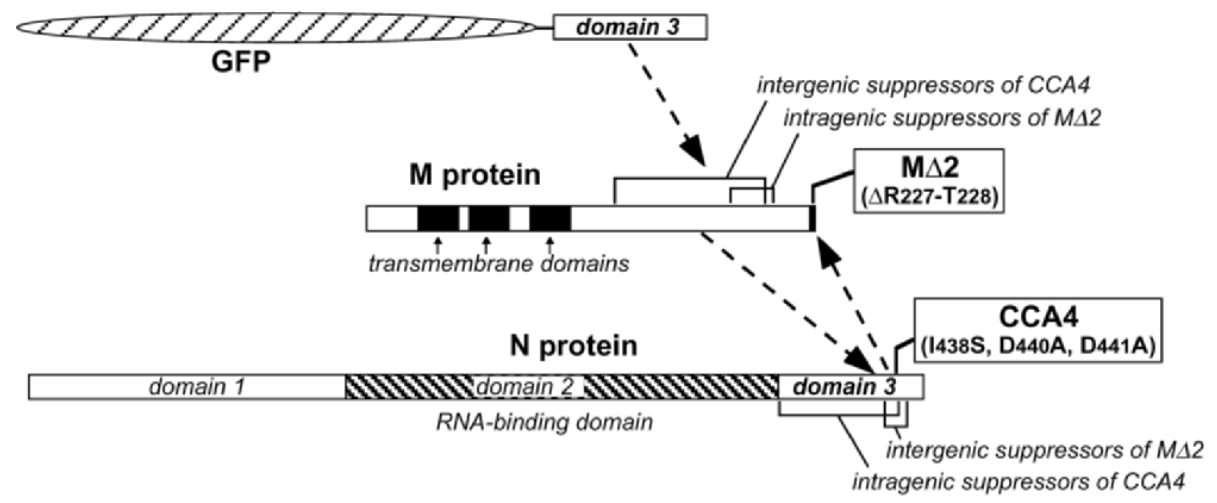

Figure 3. Intermolecular assembly interactions between the MHV $\mathrm{N}$ and $\mathrm{M}$ proteins revealed by genetic cross-talk and by transfer of domain 3 of the $\mathrm{N}$ protein to a heterologous protein (GFP). 


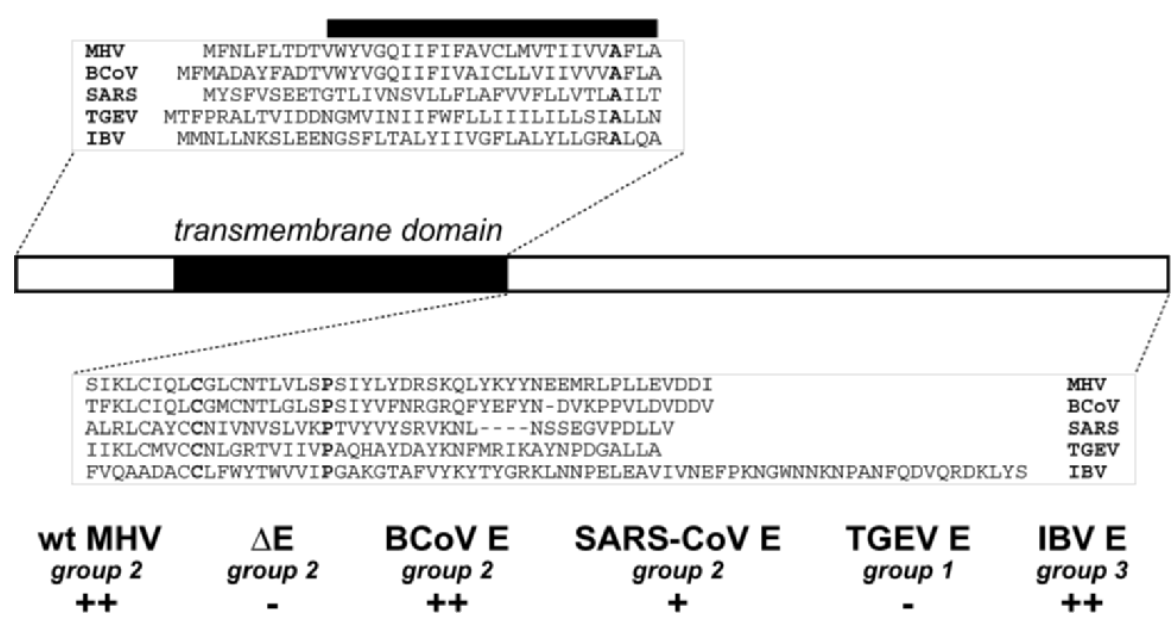

Figure 4. Alignment of the E proteins of various CoVs (top) and summary of the relative abilities of heterologous E proteins to functionally replace the E protein of MHV (bottom).

\section{THE ROLE OF E PROTEIN}

The CoV E protein is a small polypeptide $(\sim 10 \mathrm{kDa})$ that is only a minor constituent of virions. Nevertheless, it profoundly affects both VLP and virus assembly. E protein sequences diverge widely across the three $\mathrm{CoV}$ groups, but all $\mathrm{CoV}$ E proteins have the same architecture: a short hydrophilic amino terminus, followed by a large hydrophobic region, and a hydrophilic carboxy-terminal tail that constitutes one-half to two-thirds of the molecule (Fig. 4). Investigations with both the MHV and IBV E proteins are in agreement that $\mathrm{E}$ is an integral membrane protein and that its carboxy-terminal tail is cytoplasmic (corresponding to the interior of the virion). ${ }^{20,44}$ Moreover, for IBV E, the carboxy-terminal tail alone can specify targeting to the budding compartment. ${ }^{45}$ The disposition of the amino terminus is less clear, however. A lumenal (or virion-exterior) topology has been inferred for the IBV E protein amino terminus, based on its inaccessibility to antibodies at the cytoplasmic face of the Golgi membrane. ${ }^{20}$ Such a single transit across the membrane would be consistent with the transmembrane oligomers of $\mathrm{E}$ predicted by molecular dynamics simulations. ${ }^{46}$ Conversely, for $\mathrm{MHV}$, the $\mathrm{E}$ protein amino terminus has been proposed to be buried within the membrane near the cytoplasmic face, based on the reactivity of an engineered amino-terminal epitope tag at the cytoplasmic face. ${ }^{47}$ This orientation would require that the E protein hydrophobic domain form a hairpin looping back through the membrane, as envisioned in a recent biophysical analysis of the SARS-CoV E protein transmembrane domain. ${ }^{48}$

For MHV, we previously showed that particular clustered charged-to-alanine mutations constructed in the E gene rendered the virus defective in growth: assembled virions of one such mutant were found to have strikingly aberrant morphology, exhibiting pinched and elongated shapes that were rarely seen among wild-type virions. ${ }^{49}$ This finding clearly demonstrated an important role for $\mathrm{E}$ in virion assembly, as shown earlier for 
VLP assembly. ${ }^{16,17}$ We were thus surprised to find that we could successfully generate a viable, albeit highly defective, MHV recombinant $(\Delta \mathrm{E})$ in which the $\mathrm{E}$ gene, as well as genes 4 and $5 \mathrm{a}$, were entirely deleted from the viral genome. ${ }^{50}$ This indicated that the MHV E protein is a critical, but not essential, participant in virion assembly. To more specifically focus on the $\mathrm{E}$ protein, we have very recently generated an additional recombinant virus $(\mathrm{E}-\mathrm{KO})$, in which $\mathrm{E}$ protein expression has been ablated by mutation of the initiation codon and placement of stop codons in all three reading frames. The E-KO mutant exhibits the same tiny plaque phenotype and extremely defective growth as does the $\Delta \mathrm{E}$ mutant. This confirms that the phenotype observed for the $\Delta \mathrm{E}$ mutant was a direct result of the $\mathrm{E}$ gene deletion.

Similarly, it has recently been found that knockout of SARS-CoV E protein expression results in a virus that is viable in tissue culture (Almazen, DeDiego, Alvarez, and Enjuanes, this volume). By contrast, for TGEV it has been shown by two distinct reverse genetic methods that if the $\mathrm{E}$ gene is knocked out, then no viable virus can be recovered; the resulting defect can only be rescued by $\mathrm{E}$ protein provided in trans. ${ }^{51,52}$ This may indicate that basic morphogenic differences exist between the CoVs of group 2 (MHV and SARS-CoV) and group 1 (TGEV). Alternatively, it may suggest that E protein has multiple activities, one of which is essential for group $1 \mathrm{CoVs}$ but unnecessary for group 2 CoVs.

To learn more about the constraints on E protein sequence, relative to the specificity of this protein's interaction with M protein, we investigated whether E proteins from different CoVs could functionally replace that of MHV. Toward this end, we exchanged the MHV E gene with that from viruses of each of the three CoV groups. In every case, exact ORF-for-ORF substitutions were made, so that each heterologous $\mathrm{E}$ gene was expressed in the same context as MHV E (i.e., as the second ORF in a message whose unique region is bicistronic). The results of this work revealed an unexpected flexibility in the sequence requirements of the E protein (Fig. 4). As predicted, the relatively closely related $\mathrm{E}$ protein of $\mathrm{BCoV}$ (group 2) could fully substitute for the MHV E protein. Replacement of MHV E with the more phylogenetically distant group 2 SARS-CoV E protein resulted in a virus with a slightly smaller plaque size than wild-type MHV. Very surprisingly, the group 3 IBV E protein, which is extremely divergent from MHV E in both size and sequence, was completely functional in MHV infection and assembly. This could indicate that $\mathrm{E}$ protein does not need to directly contact $\mathrm{M}$ protein in order to carry out its role in virion budding. By contrast, the E protein of TGEV (group 1) was not functional in MHV; the TGEV E substitution mutant had a phenotype indistinguishable from that of the $\Delta \mathrm{E}$ mutant. These results lend further support to the notion that there are differences between the assembly mechanisms of group 1 and group 2 CoVs. We have been able to isolate multiple independent gain-of-function mutants from the TGEV E substitution recombinant, and we have found that these viruses have mutations clustering in two small regions of the TGEV E gene. Systematic analysis of these chimeric viruses should help to further elucidate the functions of E protein. 


\section{FUTURE QUESTIONS}

A great deal remains to be learned about the rules governing $\mathrm{CoV}$ assembly. One particularly intriguing question raised by the work discussed above is: does the $\mathrm{E}$ protein need to directly physically interact with the M protein, or does E act at a distance? These two possibilities are not necessarily mutually exclusive. A direct E-M interaction is suggested by the observation that there are certain unallowed interspecies combinations of $\mathrm{M}$ and $\mathrm{E}$ with respect to VLP assembly ${ }^{18}$ or virus assembly (see above). The close physical proximity of the two proteins is also supported by the demonstration that IBV E and $\mathrm{M}$ can be cross-linked to one another in infected or transfected cells. ${ }^{21}$ Conversely, some results appear to argue that $\mathrm{E}$ acts independently of $\mathrm{M}$. The individual expression of MHV or IBV E protein results in vesicles that are exported from cells. ${ }^{20,53}$ It has also been found that the expression of MHV E protein alone leads to the formation of clusters of convoluted membranous structures highly similar to those seen in CoV-infected cells, ${ }^{44}$ suggesting that one role of $\mathrm{E}$ is to induce membrane curvature in the ERGIC. The functional replacement of the MHV E protein by the highly divergent IBV E protein (see above) also suggests that a specific interaction with $M$ is not necessary for viral assembly. Moreover, in multiple revertant searches, we have yet to find a suppressor of an E gene mutant that maps in $\mathrm{M}$ or in any gene other than E. ${ }^{49}$ Similarly, we have never found intergenic suppressors of the $\mathrm{M} \Delta 2$ mutant or the N CCA4 mutant that map in $\mathrm{E}^{27}$,

${ }^{36} \mathrm{~A}$ mechanism for the independent action(s) of $\mathrm{E}$ in $\mathrm{CoV}$ assembly may be found in the recent demonstration that the SARS-CoV E protein is a cation-selective ion channel. ${ }^{54}$

A second pressing question arising from the roles of $M$ protein discussed above is: what is the structural basis for the central position of $M$ in the network of interactions that determine viral assembly? $\mathrm{M}$ associates with other monomers of $\mathrm{M}^{23}$ with the endodomain of $\mathrm{S},{ }^{24,29,30}$ with domain 3 of $\mathrm{N}^{36}$ and, possibly, with $\mathrm{E}$ and with genomic RNA. ${ }^{43}$ We have noted that the viral $\mathrm{M}$ protein is extremely sensitive to mutations. This sensitivity would be consistent with the constraints imposed by $\mathrm{M}$ needing to maintain simultaneous contacts with multiple structural partners. On the other hand, M appears able to accommodate some radically altered versions of either the $\mathrm{S}$ endodomain ${ }^{29,30}$ or $\mathrm{N}$ protein domain $3,{ }^{36}$ suggesting that $\mathrm{M}$ offers a variety of surfaces with which interacting polypeptides can establish alternative binding sites, if their primary interactions have been abolished by mutation. This versatility of $\mathrm{M}$ protein may be a component of the forces that drive $\mathrm{CoV}$ evolution, allowing the incorporation of altered or new proteins into virion envelopes. Such considerations clearly point to the necessity to obtain structural information about this crucial virion component.

We acknowledge a very productive collaboration with the laboratory of Peter Rottier on a number of the subjects discussed here. We are also grateful to Kathryn Holmes, David Brian, Carolyn Machamer, John Fleming, and Lawrence Sturman for the provision of viruses, clones, and antisera, and for very insightful discussions and advice. This work was supported by Public Health Service grants AI 39544, AI 45695, and AI 060755 from the National Institutes of Health.

\section{REFERENCES}

1. P. J. M. Rottier, in: The Coronaviridae, edited by S. G. Siddell (Plenum Press, New York, 1995), pp. 115-139.

2. J. Armstrong, H. Niemann, S. Smeekens, P. Rottier, and G. Warren, Sequence and topology of a model intracellular membrane protein, E1 glycoprotein, from a coronavirus, Nature 308, 751-752 (1984). 
3. P. Rottier, D. Brandenburg, J. Armstrong, B. van der Zeijst, and G. Warren, Assembly in vitro of a spanning membrane protein of the endoplasmic reticulum: the E1 glycoprotein of coronavirus mouse hepatitis virus A59, Proc. Natl. Acad. Sci. USA 81, 1421-1425 (1984).

4. P. J. M. Rottier, G. W. Welling, S. Welling-Wester, H. G. M. Niesters, J. A. Lenstra, and B. A. M. Van der Zeijst, Predicted membrane topology of the coronavirus protein E1, Biochemistry 25, 1335-1339 (1986).

5. C. Risco, I. M. Anton, C. Sune, A. M. Pedregosa, J. M. Martin-Alonso, F. Parra, J. L. Carrascosa, and

L. Enjuanes, Membrane protein molecules of transmissible gastroenteritis coronavirus also expose the carboxy-terminal region on the external surface of the virion, J. Virol. 69, 5269-5277 (1995).

6. K. V. Holmes, E. W. Dollar, and L. S. Sturman, Tunicamycin resistant glycosylation of a coronavirus glycoprotein: demonstration of a novel type of viral glycoprotein, Virology 115, 334-344 (1981).

7. P. J. M. Rottier, M. C. Horzinek, and B. A. M. van der Zeijst, Viral protein synthesis in mouse hepatitis virus strain A59-infected cells: effects of tunicamycin, J. Virol. 40, 350-357 (1981).

8. C. S. Ricard, C. A. Koetzner, L. S. Sturman, and P. S. Masters, A conditional-lethal murine coronavirus mutant that fails to incorporate the spike glycoprotein into assembled virions, Virus Research 39, 261-276 (1995).

9. D.-J. E. Opstelten, M. J. B. Raamsman, K. Wolfs, M. C. Horzinek, and P. J. M. Rottier, Envelope glycoprotein interactions in coronavirus assembly, J. Cell Biol. 131, 339-349 (1995).

10. V.-P. Nguyen and B. Hogue, Protein interactions during coronavirus assembly, J. Virol. 71, 9278-9284 (1997).

11. J. Tooze, S. A. Tooze, and G. Warren, Replication of coronavirus MHV-A59 in Sac- cells: determination of the first site of budding of progeny virions, Eur. J. Cell Biol. 33, 281-293 (1984).

12. P. J. M. Rottier and J. K. Rose, Coronavirus E1 protein expressed from cloned cDNA localizes in the Golgi region, J. Virol. 61, 2042-2045 (1987).

13. C. E. Machamer and J. K. Rose, A specific transmembrane domain of a coronavirus E1 glycoprotein is required for its retention in the Golgi region, J. Cell Biol. 105, 1205-1214 (1987).

14. C. E. Machamer, S. A. Mentone, J. K. Rose, and M. G. Farquhar, The E1 glycoprotein of an avian coronavirus is targeted to the cis Golgi complex, Proc. Natl. Acad. Sci. USA 87, 6944-6948 (1990).

15. J. Klumperman, J. Krijnse Locker, A. Meijer, M. C. Horzinek, H. J. Geuze, and P. J. M. Rottier, Coronavirus $\mathrm{M}$ proteins accumulate in the Golgi complex beyond the site of virion budding, J. Virol. 68 , 6523-6534 (1994).

16. H. Vennema, G.-J. Godeke, J. W. A. Rossen, W. F. Voorhout, M. C. Horzinek, D.-J. E. Opstelten, and P. J. M. Rottier, Nucleocapsid-independent assembly of coronavirus-like particles by co-expression of viral envelope protein genes, EMBO J. 15, 2020-2028 (1996).

17. E. C. W. Bos, W. Luytjes, H. van der Meulen, H. K. Koerten, and W. J. M. Spaan, The production of recombinant infectious DI-particles of a murine coronavirus in the absence of helper virus, Virology 218, 52-60 (1996).

18. P. Baudoux, C. Carrat, L. Besnardeau, B. Charley, and H. Laude, Coronavirus pseudoparticles formed with recombinant $\mathrm{M}$ and $\mathrm{E}$ proteins induce alpha interferon synthesis by leukocytes, J. Virol. 72, 8636-8643 (1998).

19. E. Mortola and P. Roy, Efficient assembly and release of SARS coronavirus-like particles by a heterologous expression system, FEBS Lett. 576, 174-178 (2004).

20. E. Corse and C. E. Machamer, Infectious bronchitis virus E protein is targeted to the Golgi complex and directs release of virus-like particles, J. Virol. 74, 4319-4326 (2000).

21. E. Corse and C. E. Machamer, The cytoplasmic tails of infectious bronchitis virus E and M proteins mediate their interaction, Virology 312, 25-34 (2003).

22. Y. Huang, Z. Y. Yang, W. P. Kong, and G. J. Nabel, Generation of synthetic severe acute respiratory syndrome coronavirus pseudoparticles: implications for assembly and vaccine production, J. Virol. 78, 12557-12565 (2004).

23. C. A. M. de Haan, H. Vennema, and P. J. M. Rottier, Assembly of the coronavirus envelope: homotypic interactions between the M proteins, J. Virol. 74, 4967-4978 (2000).

24. G.-J. Godeke, C. A. de Haan, J. W. Rossen, H. Vennema, and P. J. M. Rottier, Assembly of spikes into coronavirus particles is mediated by the carboxy-terminal domain of the spike protein, J. Virol. 74, 1566-1571 (2000).

25. L. Kuo, G.-J. Godeke, M. J. B. Raamsman, P. S. Masters, and P. J. M. Rottier, Retargeting of coronavirus by substitution of the spike glycoprotein ectodomain: crossing the host cell species barrier, J. Virol. 74, 13931406 (2000).

26. P. S. Masters and P. J. M. Rottier, Coronavirus reverse genetics by targeted RNA recombination, Curr. Topics Microbiol. Immunol. 287, 133-159 (2005).

27. L. Kuo and P. S. Masters, Genetic evidence for a structural interaction between the carboxy termini of the membrane and nucleocapsid proteins of mouse hepatitis virus, J. Virol. 76, 4987-4999 (2002). 
28. S. J. Goebel, B. Hsue, T. F. Dombrowski, and P. S. Masters, Characterization of the RNA components of a putative molecular switch in the 3' untranslated region of the murine coronavirus genome, J. Virol. 78, 669-682 (2004).

29. R. Ye, C. Montalto-Morrison, and P. S. Masters, Genetic analysis of determinants for spike glycoprotein assembly into murine coronavirus virions: distinct roles for charge-rich and cysteine-rich regions of the endodomain, J. Virol. 78, 9904-9917 (2004).

30. E. C. W. Bos, W. Luytjes, and W. J. M. Spaan, The function of the spike protein of mouse hepatitis virus strain A59 can be studied on virus-like particles: cleavage is not required for infectivity, J. Virol. 71, 9427 9433 (1997).

31. K. W. Chang, Y. W. Sheng, and J. L. Gombold, Coronavirus-induced membrane fusion requires the cysteine-rich domain in the spike protein, Virology 269, 212-224 (2000).

32. B. J. Bosch, C. A. M. de Haan, S. L. Smits, and P. J. M. Rottier, Spike protein assembly into the coronavirion: exploring the limits of itssequence requirements, Virology 334, 306-318 (2005).

33. M. M. Parker and P. S. Masters, Sequence comparison of the $\mathrm{N}$ genes of five strains of the coronavirus mouse hepatitis virus suggests a three domain structure for the nucleocapsid protein, Virology 179, 463-468 (1990).

34. P. S. Masters, Localization of an RNA-binding domain in the nucleocapsid protein of the coronavirus mouse hepatitis virus, Arch. Virol. 125, 141-160 (1992).

35. G. W. Nelson and S. A. Stohlman, Localization of the RNA-binding domain of mouse hepatitis virus nucleocapsid protein, J. Gen. Virol. 74, 1975-1979 (1993).

36. K. R. Hurst, L. Kuo, C. A. Koetzner, R. Ye, B. Hsue, and P. S. Masters, A major determinant for membrane protein interaction localizes to the carboxy-terminal domain of the mouse coronavirus nucleocapsid protein, J. Virol. 79, in press (2005).

37. D. Escors, J. Ortego, H. Laude, and L. Enjuanes, The membrane M protein carboxy terminus binds to transmissible gastroenteritis coronavirus core and contributes to core stability, J. Virol. 75, 1312-1324 (2001).

38. L. S. Sturman, K. V. Holmes, and J. Behnke, Isolation of coronavirus envelope glycoproteins and interaction with the viral nucleocapsid, J. Virol. 33, 449-462 (1980).

39. R. S. Baric, G. W. Nelson, J. O. Fleming, R. J. Deans, J. G. Keck, N. Casteel, and S. A. Stohlman, Interactions between coronavirus nucleocapsid protein and viral RNAs: implications for viral transcription, J. Virol. 62, 4280-4287 (1988).

40. R. Cologna, J. F. Spagnolo, and B. G. Hogue, Identification of nucleocapsid binding sites within coronavirus-defective genomes, Virology 277, 235-249 (2000).

41. K. Narayanan, A. Maeda, J. Maeda, and S. Makino, Characterization of the coronavirus M protein and nucleocapsid interaction in infected cells, J. Virol. 74, 8127-8134 (2000).

42. K. Narayanan and S. Makino, Cooperation of an RNA packaging signal and a viral envelope protein in coronavirus RNA packaging, J. Virol. 75, 9059-9067 (2001).

43. K. Narayanan, C. J. Chen, J. Maeda, and S. Makino, Nucleocapsid-independent specific viral RNA packaging via viral envelope protein and viral RNA signal, J. Virol. 77, 2922-2927 (2003).

44. M. J. B. Raamsman, J. Krijnse Locker, A. de Hooge, A. A. F. de Vries, G. Griffiths, H. Vennema, and P. J. M. Rottier, Characterization of the coronavirus mouse hepatitis virus strain A59 small membrane protein E, J. Virol. 74, 2333-2342 (2000).

45. E. Corse and C. E. Machamer, The cytoplasmic tail of infectious bronchitis virus E protein directs Golgi targeting, J. Virol. 76, 1273-1284 (2002).

46. J. Torres, J. Wang, K. Parthasarathy, and D. X. Liu, The transmembrane oligomers of coronavirus protein E, Biophys. J. 88, 1283-1290 (2005).

47. J. Maeda, J. F. Repass, A. Maeda, and S. Makino, Membrane topology of coronavirus E protein, Virology 281, 163-169 (2001).

48. E. Arbely, Z. Khattari, G. Brotons, M. Akkawi, T. Salditt, and I. T. Arkin, A highly unusual palindromic transmembrane helical hairpin formed by SARS coronavirus E protein, J. Mol. Biol. 341, 769-779 (2004).

49. F. Fischer, C. F. Stegen, P. S. Masters, and W. A. Samsonoff, Analysis of constructed E gene mutants of mouse hepatitis virus confirms a pivotal role for E protein in coronavirus assembly, J. Virol. 72, 7885-7894 (1998).

50. L. Kuo and P. S. Masters, The small envelope protein E is not essential for murine coronavirus replication, J. Virol. 77, 4597-4608 (2003).

51. J. Ortego, D. Escors, H. Laude, and L. Enjuanes, Generation of a replication-competent, propagationdeficient virus vector based on the transmissible gastroenteritis coronavirus genome, J. Virol. 76, 11518 11529 (2002). 
52. K. M. Curtis, B. Yount, and R. S. Baric, Heterologous gene expression from transmissible gastroenteritis virus replicon particles, J. Virol. 76, 1422-1434 (2002).

53. J. Maeda, A. Maeda, and S. Makino, Release of E protein in membrane vesicles from virus-infected cells and E protein-expressing cells, Virology 263, 265-272 (1999).

54. L. Wilson, C. McKinlay, P. Gage, and G. Ewart, SARS coronavirus E protein forms cation-selective ion channels, Virology 330, 322-331 (2004). 